\title{
Buergers Disease: Omental transplantation a novel approach of Treatment
}

\section{Gedam DS}

\author{
Dr D Sharad Gedam, editor- in- chief, IJMRR
}

Address for correspondence: Dr D Sharad Gedam, Email: editor.ijmrr@gmail.com

\begin{abstract}
Thromboangitis obliterens (TAO) also known as Buergers disease is occlusive inflammatory disease of medium and small sized arteries. In India prevelance is very high up to $45-63 \%$. Treatment options are limited. Omental transplantation may be considered as a safe and effective treatment modality with smoking cessation.
\end{abstract}

Buerger's disease is a segmental occlusive inflammatory condition of arteries and veins, characterized by thrombosis and recanalization of the affected vessels ${ }^{1,2}$. It is characterized by involvement of medium and small sized arteries. The prevalence of the disease among all patients with peripheral arterial disease ranges from values as low as 0.5 to $5.6 \%$ in Western Europe to values as high as 45 to $63 \%$ in India ${ }^{3,4}$. It usually affects the Productive age group of 40-45 years. There is history of chronic smoking in form of Bidi for a long duration in most of the patients.

Most of the time patients come to hospital with advanced disease. Various treatment options are available with inadequate response. Patients should stop smoking completely without any delay to prevent progression of disease ${ }^{5}$. Supportive care in form of preventing thermal and chemical injury, properly fitted footwear's, prevention of fungal infection and avoiding exposure to drugs and cold causing vasoconstriction is important. Role of antiinflammatory agents like steroids are controversial with no response. In TAO, arterial revascularization is usually not possible due to the diffuse segmental involvement and distal nature of the disease ${ }^{6}$. Newer drugs like Iloprost ${ }^{7}$ and Intra-arterial thrombolytic therapy with streptokinase ${ }^{8}$ has been tested in some patients with success. Sympathectomy can reduce pain but long term benefits are not clear ${ }^{9,10}$.

Krishnanand and Chanchlani et $\mathrm{al}^{11}$ in their study showed beneficial effect of Omental transplantation in Buergers disease. Other studies ${ }^{12,13,14}$ have also shown beneficial effect of Omental transplantation. Study has some limitations. Large series of patients are required to confirm beneficial effect. Follow up is also indicated to see long term effect of procedure. Doppler study and angiography should be performed before and after transplantation to evidence increased blood supply.
In various studies remote limb-salvage rate amounted to $88 \%$ to $100 \%{ }^{14,15}$. In a study of 273 patients by Agarwal et $\mathrm{al}^{12}$ showed good results in $94 \%$ of patients in $0-5$ years follow up. In long term follow up from 5-15 years 85\% showed good results.

To conclude Omental transplantation with cessation of smoking may be considered as a safe and effective treatment option for Buergers disease. All other treatment modalities have limited role in progression of disease.

Funding: Nil

\section{Conflict of interest: Nil}

\section{References}

1. Buerger L. Thromboangiitis obliterans: a study of the vascular lesions leading to presenile gangrene. Am J Med Sci. 1908;136:567-580.

2. Buerger L. The circulatory disturbance of the extremities: including gangrene, vasomotor and trophic disorders. Philadelphia, Saunders; 1924.

3. Cachovan M. Epidemiologic und geographisches Verteilungsmuster der Thromboangiitis obliterans. In: Heidrich $\mathrm{H}$, editor. Thromboangiitis obliterans Morbus Winiwarter-Buerger.Stuttgart, Germany Georg Thieme; 1988. pp. 31-36.

4. Matsushita M, Nishikimi N, Sakurai T, Nimura Y. Decrease in prevalence of Buerger's disease in Japan. Surgery. 1998;124:498-502. [PubMed] 
5. Shionoya S. What is the Buerger's disease? World J Surg. 1983;7:544-551. doi: 10.1007/BF01655948.

6. Olin JW, Young JR, Graor RA, Ruschhaupt WF, Bartholomew JR. The changing clinical spectrum of thromboangiitis obliterans (Buerger's disease) Circulation. 1990;82:IV3-8.

7. Cachovan M. Epidemiologic und geographisches Verteilungsmuster der Thromboangiitis obliterans. In: Heidrich H, editor. Thromboangiitis obliterans Morbus Winiwarter-Buerger.Stuttgart, Germany Georg Thieme; 1988. pp. 31-36.

8. Matsushita M, Nishikimi N, Sakurai T, Nimura Y. Decrease in prevalence of Buerger's disease in Japan. Surgery. 1998;124:498-502

9. Chander J, Singh L, Lal P, Jain A, Lal P, Ramteke VK. Retroperitoneoscopic lumbar sympathectomy for buerger's disease: a novel technique. JSLS. 2004;8:291-296.

10. Lau H, Cheng SW. Buerger's disease in Hong Kong: a review of 89 cases. Aust N Z J Surg.1997;67:264-269.
11. Krishnanand, Chanchlani R. Omental Transplantation for limb salvage in Buerger's disease - a study in a tertiary care hospital, Bhopal. Int J Med Res Rev 2013;1(3):92-98.

12. Agarwal VK. Long-term results of omental transplantation in chronic occlusive arterial disease (Buerger'sdisease). Int Surg. 2005 JulAug;90(3):167-74.

13. Bhat MA, Zaroo MI, Darzi MA. Omental transplantation for critical limb ischemia in Buerger's disease.. Plast Reconstr Surg. 2007 May;119(6):1979-80.

14. Vachev AN, Mikhaĭlov MS, Novozhilov AV. [Microsurgical autotransplantation of the greater omentum to a lower limb in patients with critical ischaemia accompanying thromboangiitis obliterans]. Angiol Sosud Khir. 2008;14(3):107-10

15. Vachev AN, Mikhaǔlov MS, Novozhilov AV, Chernovalov DA. Simultaneous revascularization of both limbs by means of transplantation of the greater omentum on a vascular pedicle in patients with thromboangiitis obliterans. Angiol Sosud Khir. 2010;16(3):139-42

How to cite this article?

Gedam DS. Buergers Disease: Omental transplantation a novel approach of Treatment. Int J Med Res Rev 2013;1(3):74-75. doi:10.17511/ijmrr.2013.i03.01 